\title{
Temporal genetic variation in Aedes aegypti populations in Ho Chi Minh City (Vietnam)
}

\author{
K Huber ${ }^{1}$, Luu Le Loan ${ }^{2}$, Tran Huu Hoang ${ }^{2}$, Tran Khanh Tien ${ }^{2}$, F Rodhain ${ }^{1}$ and A-B Failloux ${ }^{1}$ \\ ${ }^{1}$ Unité d'Ecologie des Systèmes Vectoriels, Institut Pasteur, 25 rue du Dr. Roux, 75724 Paris cedex 15, France; ${ }^{2}$ Institut Pasteur of \\ Ho Chi Minh City, Unité d'Entomologie médicale, 167 Duong Pasteur, Ho Chi Minh City, Vietnam
}

\begin{abstract}
Aedes aegypti, the main vector of dengue viruses in Asia, displays variation in population density over time. The larval habitats of this species being unevenly distributed and transient (depending on cycles of drought and flood), the forces generating temporal variation in gene frequecies in populations are studied. We sampled seven mosquito populations from Ho Chi Minh City (Vietnam) and its suburbs on five occasions between April 1999 and August 2000. We investigated genetic variation by studying isoenzyme and microsatellite polymorphism and susceptibility to a dengue 2 virus strain. Ae. aegypti populations collected during the dry sea-
\end{abstract}

son (January-April) showed genetic differentiation ( $F_{S T}=0.016, P<10^{-6}$ for isoenzymes) and showed more differentiated infection rates of the dengue 2 virus. The genetic structure of the population is less marked during the rainy season $\left(F_{S T}=0.081, P<10^{-6}\right)$. Thus, environmental factors, such as rainfall and factors related to human activity, such as breeding site density and insecticide treatment, control the genetic structure of $A e$. aegypti populations in the short term. The implications of studies of this kind for the design of future control programmes are discussed. Heredity (2002) 89, 7-14. doi:10.1038/sj.hdy.6800086

Keywords: Aedes aegypti; dengue; temporal variation; Vietnam

\section{Introduction}

Before the 1950s, Aedes albopictus was the main vector of dengue viruses in South-East Asia. It was responsible for dengue transmission in rural or peri-urban areas, causing only sporadic cases and local outbreaks. The introduction in Vietnam at the beginning of the 20th century of Ae. aegypti (Bernard and Bauche, 1913) has modified this equilibrium. Since then, Ae. aegypti has progressively pushed Ae. albopictus back to the commuter belt because of interspecific competition, colonizing most urban and peri-urban Asian habitats. Coincidentally, dengue haemorrhagic fever has appeared in Vietnam (Mihov et al, 1959). All four dengue serotypes are now maintained in an urban endemic cycle in most Asian cities. The change in the pattern of dengue transmission in Asia is at least partly due to the introduction of Ae. aegypti, which is responsible for most urban epidemics. In Ho Chi Minh City, Ae. aegypti larvae inhabit various types of water container: indoor containers (pots, small jars and ant traps) and outdoor plastic waste in town centres, and mainly drums and domestic earthenware jars in the suburbs, which generally do not have mains water supplies (Huber et al, 2000). The breeding season of the mosquito extends throughout the year. However, mosquito densities decline during the dry season and peak in the rainy season, coinciding with a period of high dengue incidence.

Correspondence: Dr A-B Failloux, Institut Pasteur, Ecologie des Systèmes Vectoriels, 25 rue du Dr Roux, 75724 Paris cedex 15, France. E-mail: afaillou@pasteur.fr

Received 1 October 2001; accepted 25 February 2002
Spatial genetic differentiation of Ae. aegypti populations has been widely investigated. Tran Khanh Tien et al (1999) detected high levels of differentiation in mosquito populations from Ho Chi Minh City by isoenzyme electrophoresis. Later studies (K Huber, personal communication) gave greater definition to the differentiation pattern of populations, using six microsatellite loci. Variations in isoenzymes and microsatellites have provided evidence that water storage habits and human densities affect the level of differentiation of the mosquito populations. The number and proximity of breeding sites and the density of human populations (providing a supply of blood for the females), may affect the dispersal of mosquitoes, thereby modifying the genetic differentiation of their populations. This raises questions concerning the extent to which Ae. aegypti populations in urban centres evolve as independent units and show local adaptations.

In addition to studies of the spatial distribution of neutral genes (isoenzymes or microsatellites) in subdivided populations, which is generally shaped by genetic drift and migration (Slatkin, 1985), temporal analyses may provide information about the forces responsible for genetic changes over a short time scale (ie, a few generations). Little is known about the genetic changes in Ae. aegypti populations associated with temporal fluctuations of water availability and consequently in population size. Ae. aegypti tends to occupy unevenly distributed permanent or transient habitats subject to cycles of drought and flood associated with the pattern of rainfall. We have conducted an analysis based on seven Ae. aegypti populations subjected to seasonal changes using neutral genes and also variation in susceptibility to dengue 2 virus. 


\section{Materials and methods}

\section{Mosquito samples (Figure 1)}

Seven sites were sampled in Ho Chi Minh City and its suburbs: one from the 7 th district (Phu Thuan ward (1.PHU)), two from Nha Be (town of Nha Be (2.NHA) and Phuoc Kien village (3.NBE)), three from Binh Chanh (Binh Chanh village (4.BIN), Tan Quy Tay village (5.BCH) and Binh Loi village (6.LOI)) and one from Thu Duc (Hiep Binh Phuoc village (7.THU)). Mosquito samples were collected on three occasions in 1999: at the beginning of the rainy season (April), during the rainy season (August) and at the beginning of the dry season (end of November). Samples were then collected on two occasions in 2000 (March and August) (Figure 1). Rainfall varies from year to year, with a mean of $2000 \mathrm{~mm}$ of rainfall per year. The samples collected consisted of larvae or pupae, which were reared until the imago stage in an insectarium (temperature: $25 \pm 1^{\circ} \mathrm{C}$, relative humidity: $80 \pm 10 \%$ and $12 \mathrm{~h}$ light/dark cycle). $F_{0}$ adults were allowed to blood feed on mice and the eggs laid by them were collected. The batches of eggs obtained were hatched and larvae reared until the imago stage $\left(F_{1}\right.$ adults). $\mathrm{F}_{0}$ adults were stored at $-80^{\circ} \mathrm{C}$ for isoenzyme and microsatellite polymorphism analysis and $F_{1}$ adults were orally infected with a dengue 2 virus. The Paea strain of Ae. aegypti was used as a control for mosquito infection (Vazeille-Falcoz et al, 1999) and as a mobility control for isoenzyme polymorphism (Tran Khan Tien et al, 1999).

\section{Experimental infection of mosquitoes}

Two infection assays were carried out for each $F_{1}$ mosquito sample $\left(\mathrm{F}_{2}\right.$ mosquitoes were used if too few $F_{1}$

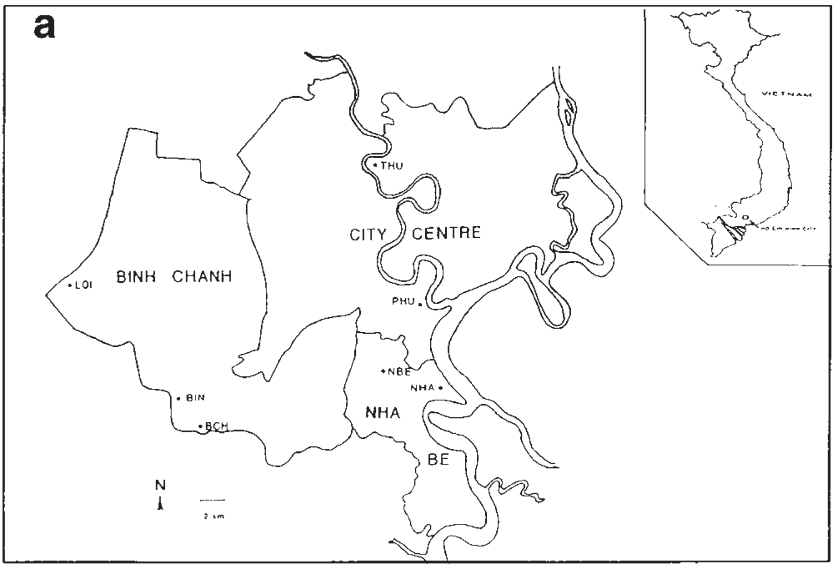

b

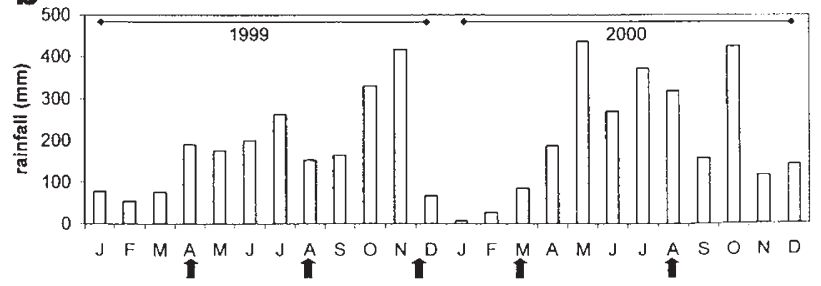

Figure 1 (a) Map of Ho Chi Minh City showing the locations from which Aedes aegypti samples were taken. (b) Monthly rainfall totals in Ho Chi Minh City from January 1999 to December 2000. Arrows indicate sampling events. adults were available) (for more details, see VazeilleFalcoz et al, 1999). It was first determined the amount of virus necessary to infect $50-70 \%$ of the control Paea strain mosquitoes which was done by feeding mosquitoes with serial dilutions of the viral stock suspension. The titer of the feeding suspension that was given to 50-70\% infected females was estimated and was later used to infect mosquitoes collected in the field $\left(10^{7.2} \mathrm{MID}_{50}\right)$.

Fisher's exact test was used to compare proportions of surviving infected females 14 days after infection. We used the STRUC subprogramme to calculate an unbiased estimate of the exact $P$ value (Raymond and Rousset, 1995).

\section{Isoenzyme polymorphism}

Individual mosquitoes were ground in $25 \mu \mathrm{l}$ of distilled water and the resulting homogenate was centrifuged $\left(15000 \mathrm{~g}, 5 \mathrm{~min}\right.$ at $\left.+4^{\circ} \mathrm{C}\right)$ : the pellet was used for DNA extraction and the supernatant for starch gel electrophoresis. Seven enzyme systems were studied (for more details, see Tran Khanh Tien et al, 1999; Paupy et al, 2000). Staining procedures used to detect specific enzyme activity were as previously described (Pasteur et al, 1988). A strain developed from an isofemale lineage of $A e$. aegypti Paea was used as a mobility control. Alleles were scored with respect to the most common allele obtained at each locus in the Paea strain.

\section{Microsatellite polymorphism}

DNA was individually extracted from pellets in DNAzol solution (Gibco BRL) (for more details, see Huber et al, 2001). Five microsatellite loci were studied: C2A8, 34/72, T3A7, AED19, 38/38 (for more information, see Huber et al, 2001). Two $\mu \mathrm{l}$ of an individual mosquito DNA sample were used as template in the polymerase chain reaction (PCR) which had a final volume of $12.5 \mu \mathrm{l}$ and contained $1 \times$ buffer (Eurobio), $1.2 \mathrm{mM} \mathrm{MgCl} 2,60 \mu \mathrm{M}$ of each dNTP, 5 pmoles of each primer and 0.25 units of Taq polymerase (Eurobio). Amplifications were performed in a 9600 thermal cycler (Perkin-Elmer). The reaction conditions were 5 cycles of $2 \mathrm{~min}$ at $96^{\circ} \mathrm{C}, 30 \mathrm{sec}$ annealing at locus-specific annealing temperature (Ta) and $1 \mathrm{~min} 15 \mathrm{sec}$ extension at $72^{\circ} \mathrm{C}$, followed by 25 cycles $\left(30 \mathrm{sec}\right.$ at $95^{\circ} \mathrm{C}, 30 \mathrm{sec}$ at Ta and $1 \mathrm{~min} 15 \mathrm{sec}$ at $\left.72^{\circ} \mathrm{C}\right)$. A terminal elongation step (5 min at $72^{\circ} \mathrm{C}$ ) ended the amplification programme. One primer (1.5 pmoles) was end-labelled with one of the three different fluorescent phosphoramidite dyes (FAM, HEX or NED) appropriate for ABI PRISM instruments. PCR reaction products were diluted to $1 / 20$ th with distilled water. Then, $1 \mu \mathrm{l}$ of each product was pooled with other compatible products according to the product length and the fluorescent dye. Pools were prepared by adding $0.5 \mu \mathrm{l}$ of internal size standard $400 \mathrm{HD}$ ROX (Perkin-Elmer) and deionised formamide for a final volume of $20 \mu$ l. The size standard contains DNA fragments fluorescently labelled with the NHS-ester dye ROX, ranging in size from 50 to $400 \mathrm{bp}$. After heat denaturation at $95^{\circ} \mathrm{C}$ for $3 \mathrm{~min}, \mathrm{PCR}$ products were chilled on ice. The PCR products/size standard mixture were electrophoresed in an ABI Prism 310 sequencer (Perkin-Elmer). Genotype data were analysed using GeneScan Analysis software (Perkin-Elmer), which automatically determined the fluorescence signal and expressed it as a peak in an electrophoregram. 


\section{Statistical analysis}

We calculated allele frequencies for each sample and sampling date. We assessed deviation from Hardy-Weinberg equilibrium and genotypic linkage disequilibrium for each sample and sampling date, and tested for differentiation between samples for each sampling date, using a recent update (3.1) of GENEPOP software (Raymond and Rousset, 1995). $F_{I S}$ and $F_{S T}$ were calculated according to the formula of Weir and Cockerham (1984). We assessed genetic structure: (1) in the various populations at each sampling date, and (2) for one population for all five sampling dates. The levels of significance for multiple tests were adjusted by the sequential method of Bonferroni (Holm, 1979).

\section{Results}

\section{Mosquito infection rates}

For the 43 mosquito samples tested (Table 1), we obtained infection rates of $24.1 \%$ (LOIa, 3rd collection) to $100 \%$ (NHAa, 1st collection). If two replicates had been carried out for a particular sample, we compared infection rates between the two replicates. We rejected the null hypothesis that infection rates were similar in all replicates $(P<0.05)$ for three samples (NHA, BIN and LOI) from the first sample collection, two samples (BIN and $\mathrm{BCH}$ ) from the 3 rd sample collection, two samples (NHA and BIN) from the 4th sample collection and three samples (BIN, BCH and THU) from the 5th sample collection. For these samples, further analysis was carried out only for the replicate with the larger sample size. We compared the infection rates obtained in the assays with those obtained for the corresponding control. In nine cases, a significant difference was observed: PHUa, NHAa, BINb from the 1st collection, NBEb from the 2nd collection, NHAa, BINa, BINb, BCHb from the 4th collection, and $\mathrm{BCHb}$ from the 5 th collection. In analysis of all the samples at each collection date, the overall $P$ value obtained in Fisher's exact test was highly significant (Table 1). Three groups were defined, based on location: (1) two sites (THU and PHU) corresponding to the city centre, (2) three sites (BIN, BCH and LOI) in the Binh Chanh district and (3) two sites (NHA and NBE) in the Nha Be district. Homogeneity in infection rates was observed only for Binh Chanh samples $(P=1)$ and Nha Be samples $(P=0.81)$ for the first collection, for Binh Chanh samples $(P=0.05)$ for the 3rd collection and for Nha Be samples $(P=0.1)$ for the 5 th collection. All other comparisons showed infection rates to be heterogeneous $(P<0.05)$.

If we grouped collections (six sites only) according to seasons (Table 2) - rainy season (1st, 2 nd and 5th collections) and dry season (3rd and 4th collection) infection rates were homogeneous for PHU $(P=0.22)$, NHA $(P=0.21)$ and LOI $(P=0.18)$ in the rainy season and for NBE $(P=0.59)$ in the dry season.

\section{Temporal genetic variation}

(1) isoenzyme polymorphism: We tested pairs of loci for genotypic disequilibrium: 31 of the 519 possible tests showed significant (5\% level) disequilibrium (data not shown). All 31 involved combinations of Hk1, Hk2 and Hk3, or Got1 and Got2 suggesting that these combi- nations could not be considered to be statistically inde-

pendent. We therefore used only Got1 and Hk1 for subsequent analysis.

For each collection date, we tested for Hardy-Weinberg equilibrium for each locus in each sample, using the probability test. Significant $P$ values $(P<0.05)$ were obtained only for Hk1 - NBE in the 4th collection, probably due to heterozygote excess (details not shown). No disequilibrium was detected in any of the 260 possible combinations of the remaining seven loci in pairs (data not shown).

We analysed genetic differentiation by comparing genotype frequencies and distributions. Differentiation, evaluated by estimating $F_{S T}$, was highly significant if we considered all samples at each collection date (Table 3). $F_{S T}$ values were approximately two to seven times higher for the 3rd collection $\left(F_{S T}=+0.080\right)$ than for the other collections. If we grouped together samples from the same collection site (city centre, Binh Chanh district and Nha Be district), differentiation was highly significant in all but three cases: between the two city centre samples for the 2 nd collection $(P=0.34)$ and between the two samples from Nha Be for the 3rd collection $(P=0.97)$ and for the 5 th collection $(P=0.22)$. Analysis of the two city centre samples showed that the level of population differentiation was low for the 1st collection $\left(F_{S T}=+0.019\right)$ and the 2 nd collection $\left(F_{S T}=-0.004\right)$, had increased by the $3 \mathrm{rd}$ collection $\left(F_{S T}=+0.210\right)$ and then fell in the 4 th collection $\left(F_{S T}=+0.036\right)$ and the 5 th collection $\left(F_{S T}=+0.052\right)$. A similar pattern was observed for the three samples from Binh Chanh except that population differentiation was at its highest level in the 4 th collection $\left(F_{S T}=+0.142\right)$. However, the two samples of Nha Be displayed a gradual decrease in population differentiation which from the 1st collection $\left(F_{S T}=+0.031\right)$ to the 3 rd collection $\left(F_{S T}=-0.004\right)$, and increased thereafter to peak in the 4th collection $\left(F_{S T}=+0.038\right)$. We also assessed differentiation as a function of season (Table 5). Significant differentiation was observed between samples if all collections dates were considered $\left(P<10^{-6}\right)$. Significant differentiation was observed between samples in both the rainy season and the dry season. The level of population differentiation was three (BIN) to 14 (PHU and $\mathrm{BCH}$ ) times higher in the dry season than in the rainy season, except for NHA samples which displayed twice as much population differentiation $\left(F_{S T}=+0.025\right)$ in the rainy season as in the dry season $\left(F_{S T}=+0.012\right)$.

(2) microsatellite polymorphism: All five microsatellite loci studied were variable, with between four (38/38) and 12 (T3A7) alleles detected at the different loci. Nineteen rare alleles, specifically private alleles (Slatkin, 1985), were observed at the microsatellite loci. Most were detected in samples from the city centre (4/9) and Nha Be (4/9) for the 1st collection and in samples from Binh Chanh (6/10) for the 3rd collection. Allele changes were observed between the 1st and the 3rd collections: 18 of the 36 alleles detected at the five loci were present in samples from both collections; nine were observed only in samples from the 1st collection and nine only in samples from the 3rd collection. Significant deviation of allele frequencies from Hardy-Weinberg equilibrium was observed after Bonferroni correction in five of 31 tests for the 1st collection and three of 30 in the 3rd collection (Table 4). In the 1st collection, three of these cases of 
10

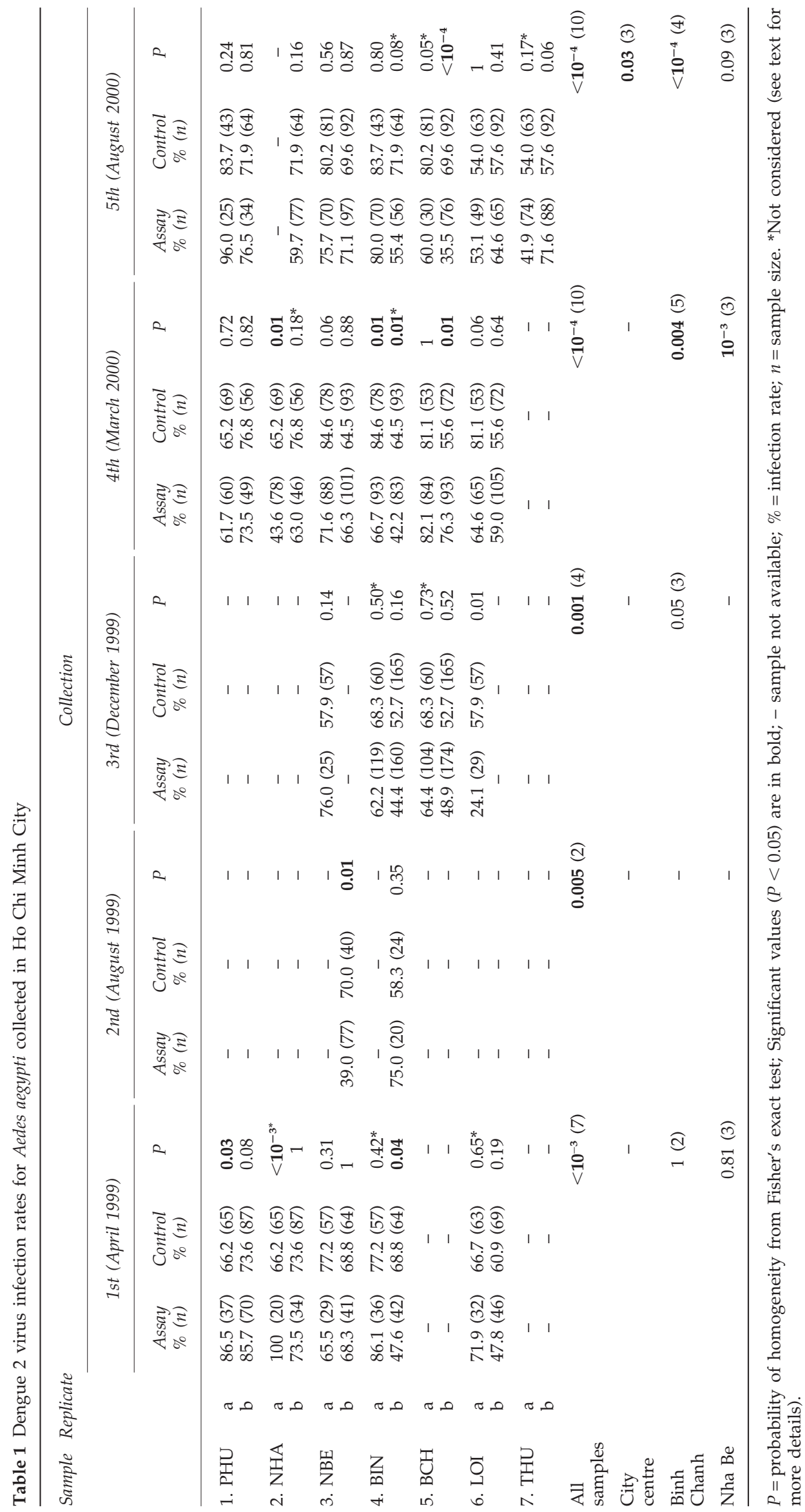


Table 2 Probabilities of homogeneity of infection rates estimated among Aedes aegypti samples according to season

\begin{tabular}{|c|c|c|c|c|c|c|}
\hline & \multicolumn{2}{|c|}{ All collections } & \multicolumn{2}{|c|}{ Rainy season ${ }^{a}$} & \multicolumn{2}{|c|}{ Dry season ${ }^{b}$} \\
\hline & $n$ & $P$ & $n$ & $P$ & $n$ & $P$ \\
\hline 1. PHU & 6 & 0.004 & 4 & 0.22 & - & - \\
\hline 2. NHA & 3 & 0.010 & 2 & 0.21 & - & - \\
\hline 3. NBE & 8 & $<10^{-4}$ & 5 & $<10^{-4}$ & 3 & 0.59 \\
\hline 4. BIN & 5 & $<10^{-4}$ & 3 & 0.002 & 2 & 0.0004 \\
\hline 5. $\mathrm{BCH}$ & 4 & $<10^{-4}$ & - & - & 3 & $<10^{-4}$ \\
\hline 6. LOI & 6 & 0.005 & 3 & 0.18 & 3 & 0.001 \\
\hline
\end{tabular}

${ }^{\mathrm{a} C o l l e c t i o n s ~ 1,2}$ and 5; ${ }^{\mathrm{b}}$ Collections 3 and $4 ; n=$ number of samples and replicates; $P=$ probability of homogeneity from Fisher's exact test. Significant values $(P<0.05)$ are in bold; - not possible.

deviation from Hardy-Weinberg equilibrium corresponded to heterozygote deficits (NBE at the AED19 locus, NBE at T3A7 locus and THU at T3A7 locus) and one correspond to heterozygote excess (LOI at 34/72). In the 3rd collection, all three cases of deviation from Hardy-Weinberg equilibrium were due to heterozygote deficits (THU at C2A8, NHA at T3A7 and BCH at T3A7). If the heterozygote deficits were caused by the Walhund effect (ie, a subdivided population with unequal allele frequencies), deviations would be found throughout the genome. Null alleles also generate apparent heterozygote deficits. Mutations or deletions affecting sequences flanking the microsatellite may prevent PCR amplification, resulting in a heterozygote being scored as a homozygote. Non-random association between pairs of loci was ruled out in all samples except the 34/72 to $38 / 38$ combination for the NBE sample in the 1st collection. In this case, the non-random association was probably due to genetic drift rather than selection $\left(D_{I S}<D_{S T}\right.$ and $\mathrm{D}_{I S}^{\prime}>\mathrm{D}_{S T}^{\prime}$ : Ohta, 1982).

Significant differentiation between samples was observed for the 1st collection $\left(F_{S T}=+0.095, P<10^{-6}\right)$ and the 3 rd collection $\left(F_{S T}=+0.089, P<10^{-6}\right)$ (Table 3 ). Differentiation remained high if samples were grouped according to collection site $\left(F_{S T}\right.$ values between +0.0576 and $+0.1512)$ and was significant $(P<0.05)$ for the 1 st collection and the 3rd collection, except for samples from the
Nha Be district in the 3rd collection. Mosquito populations showed no significant differentiation in the Nha Be district $\left(F_{S T}=+0.010, P=0.18\right)$. Lower levels of genetic differentiation were observed in samples from the city centre than in samples collected in Binh Chanh, regardless of the collection date. If we compared differentiation between two collections at each collection site (Table 5), the highest level of differentiation were those for BIN $\left(F_{S T}=+0.224\right)$ and $\mathrm{BCH}\left(F_{S T}=+0.180\right)$, with large differences in the genetic structure of the population between the two seasons.

\section{Discussion}

This survey of genetic variability over time in Ae. aegypti from Ho Chi Minh City shows that genetic differentiation, estimated by isoenzyme polymorphism, tends to decrease during the rainy season and to increase significantly at the start of the dry season. Within a sample, allelic frequencies at microsatellite loci were constant for the first collection (corresponding to the start of the rainy season) and the 3rd collection (start of the dry season). However, allelic composition changed considerably between the two seasons. We also observed variations in susceptibility to dengue 2 virus infection, which remained constant during the rainy season. Only samples from the Nha Be district showed a different pattern: a lower level of differentiation, as shown by isoenzyme and microsatellite profiles, in the dry season, and highly variable rates of infection with dengue virus in the rainy season. These results support the hypothesis that the genetic structure and susceptibility to dengue virus of Ae. aegypti populations are under temporal control.

Ecological surveys of Ae. aegypti populations in Ho Chi Minh City suggest that vector density displays seasonal variation (Huber et al, 2000). The abundance of Ae. aegypti depends on the availability of water-filled containers, and the water-storage habits of humans, which affect the breeding pattern of this species (Moore et al, 1978). Mosquito population densities start to rise at the beginning of the rainy season (usually in April). They gradually increase thereafter, reaching a peak in June and July. The mosquito population generally reaches a maximum after peak rainfall. Running water is not available in some of the suburbs of Ho Chi Minh City and drinking water is

Table 3 Aedes aegypti differentiation based on isoenzyme and microsatellite polymorphism analysis according to collection sites and collection dates

\begin{tabular}{|c|c|c|c|c|c|c|c|c|}
\hline \multirow[t]{2}{*}{ Comparison } & \multirow[t]{2}{*}{$n$} & \multicolumn{5}{|c|}{ Isoenzyme $F_{S T}(P)$} & \multicolumn{2}{|c|}{ Microsatellite $F_{S T}(P)$} \\
\hline & & $\begin{array}{c}1 s t \\
(04-1999)\end{array}$ & $\begin{array}{c}2 n d \\
(08-1999)\end{array}$ & $\begin{array}{c}3 r d \\
(12-1999)\end{array}$ & $\begin{array}{c}4 \text { th } \\
(03-2000)\end{array}$ & $\begin{array}{c}5 \text { th } \\
(08-2000)\end{array}$ & $\begin{array}{c}1 s t \\
(04-1999)\end{array}$ & $\begin{array}{c}3 r d \\
(12-1999)\end{array}$ \\
\hline All samples & 7 & $\begin{array}{c}0.015 \\
\left(<\mathbf{1 0}^{-4}\right)\end{array}$ & $\begin{array}{c}0.012 \\
\left(<\mathbf{1 0}^{-4}\right)\end{array}$ & $\begin{array}{c}0.080 \\
\left(<\mathbf{1 0}^{-6}\right)\end{array}$ & $\begin{array}{c}0.057 \\
\left(<\mathbf{1 0}^{-6}\right)\end{array}$ & $\begin{array}{c}0.016 \\
\mathbf{( 0 . 0 0 0 1 )}\end{array}$ & $\begin{array}{c}0.095 \\
\left(<10^{-6}\right)\end{array}$ & $\begin{array}{c}0.089 \\
\left(<10^{-6}\right)\end{array}$ \\
\hline City centre & 2 & $\begin{array}{c}0.019 \\
(\mathbf{0 . 0 0 0 3 )}\end{array}$ & $\begin{array}{c}-0.004 \\
(0.34)\end{array}$ & $\begin{array}{c}0.210 \\
\left(<\mathbf{1 0}^{-6}\right)\end{array}$ & $\begin{array}{c}0.036 \\
\left(<\mathbf{1 0}^{-6}\right)\end{array}$ & $\begin{array}{c}0.052 \\
\mathbf{( 0 . 0 0 2 )}\end{array}$ & $\begin{array}{c}0.063 \\
\mathbf{( 0 . 0 0 2 )}\end{array}$ & $\begin{array}{l}0.044 \\
\mathbf{( 0 . 0 2 )}\end{array}$ \\
\hline Binh Chanh & 3 & $\begin{array}{c}0.013 \\
\mathbf{( 0 . 0 0 5 )}\end{array}$ & $\begin{array}{c}0.016 \\
\left(<10^{-4}\right)\end{array}$ & $\begin{array}{c}0.116 \\
\left(<\mathbf{1 0}^{-6}\right)\end{array}$ & $\begin{array}{c}0.142 \\
\left(<\mathbf{1 0}^{-6}\right)\end{array}$ & $\begin{array}{l}0.015 \\
\mathbf{( 0 . 0 1 )}\end{array}$ & $\begin{array}{c}0.151 \\
\left(<10^{-6}\right)\end{array}$ & $\begin{array}{c}0.120 \\
\left(<10^{-6}\right)\end{array}$ \\
\hline Nha Be & 2 & $\begin{array}{c}0.031 \\
\mathbf{( 0 . 0 0 6 )}\end{array}$ & $\begin{array}{r}0.012 \\
(\mathbf{0 . 0 0 4 )}\end{array}$ & $\begin{array}{c}-0.004 \\
(0.97)\end{array}$ & $\begin{array}{c}0.038 \\
\left(<10^{-6}\right)\end{array}$ & $\begin{array}{l}0.014 \\
(0.22)\end{array}$ & $\begin{array}{c}0.058 \\
\left(<\mathbf{1 0}^{-4}\right)\end{array}$ & $\begin{array}{l}0.010 \\
(0.18)\end{array}$ \\
\hline
\end{tabular}

$P=$ Probability of homogeneity (see text for more details); Significant values $(P<0.05)$ are in bold; - sample not available. 
Table 4 Microsatellite variability, inbreeding coefficient $\left(F_{I S}\right)$ and $P$ values estimated for Aedes aegypti samples collected in Ho Chi Minh City during rainy and dry seasons

\begin{tabular}{|c|c|c|c|c|c|c|c|}
\hline \multirow[t]{2}{*}{ Samples } & & \multicolumn{6}{|c|}{ Locus } \\
\hline & & $\mathrm{C} 2 \mathrm{~A} 8$ & $34 / 72$ & T3A7 & AED19 & $38 / 38$ & All \\
\hline $\begin{array}{l}\text { 1st Coll } \\
\text { PHU }\end{array}$ & $\begin{array}{c}\text { son) } \\
n \\
\text { Nall } \\
F_{I S} \\
P\end{array}$ & $\begin{array}{c}20 \\
3 \\
-0.036 \\
1.00\end{array}$ & $\begin{array}{c}20 \\
4 \\
+0.201 \\
0.004\end{array}$ & $\begin{array}{c}17 \\
6 \\
+0.133 \\
0.544\end{array}$ & $\begin{array}{c}21 \\
2 \\
+0.467 \\
0.144\end{array}$ & $\begin{array}{r}23 \\
1 \\
- \\
-\end{array}$ & $\begin{array}{c}+0.181 \\
0.042\end{array}$ \\
\hline NHA & $\begin{array}{c}n \\
\text { Nall } \\
F_{I S} \\
P\end{array}$ & $\begin{array}{c}22 \\
2 \\
-0.313 \\
0.269\end{array}$ & $\begin{array}{c}22 \\
3 \\
-0.033 \\
0.003\end{array}$ & $\begin{array}{c}18 \\
4 \\
+0.421 \\
<\mathbf{1 0}^{-3}\end{array}$ & $\begin{array}{c}20 \\
3 \\
-0.192 \\
1.00\end{array}$ & $\begin{array}{r}25 \\
1 \\
- \\
-\end{array}$ & $\begin{array}{r}+0.033 \\
<10^{-3}\end{array}$ \\
\hline NBE & $\begin{array}{c}n \\
\text { Nall } \\
F_{I S} \\
P\end{array}$ & $\begin{array}{c}39 \\
2 \\
-0.206 \\
0.319\end{array}$ & $\begin{array}{c}39 \\
3 \\
-0.163 \\
<\mathbf{1 0}^{-3}\end{array}$ & $\begin{array}{r}46 \\
5 \\
+0.391 \\
<\mathbf{1 0}^{-3}\end{array}$ & $\begin{array}{r}42 \\
4 \\
+0.882 \\
<\mathbf{1 0}^{-4}\end{array}$ & $\begin{array}{c}46 \\
3 \\
+0.164 \\
0.01\end{array}$ & $\begin{array}{r}+0.160 \\
<10^{-4}\end{array}$ \\
\hline BIN & $\begin{array}{c}n \\
\text { Nall } \\
F_{I S} \\
P\end{array}$ & $\begin{array}{c}27 \\
3 \\
-0.241 \\
0.643\end{array}$ & $\begin{array}{c}27 \\
3 \\
-0.270 \\
0.292\end{array}$ & $\begin{array}{c}21 \\
5 \\
+0.100 \\
0.104\end{array}$ & $\begin{array}{c}18 \\
2 \\
+0.460 \\
0.169\end{array}$ & $\begin{array}{c}22 \\
2 \\
-0.182 \\
0.662\end{array}$ & $\begin{array}{c}-0.103 \\
0.268\end{array}$ \\
\hline $\mathrm{BCH}$ & $\begin{array}{c}n \\
\text { Nall } \\
F_{I S} \\
P\end{array}$ & $\begin{array}{c}19 \\
2 \\
-0.029 \\
1.00\end{array}$ & $\begin{array}{c}19 \\
3 \\
-0.059 \\
0.025\end{array}$ & $\begin{array}{c}26 \\
5 \\
+0.286 \\
0.041\end{array}$ & $\begin{array}{c}25 \\
2 \\
+0.204 \\
0.552\end{array}$ & $\begin{array}{r}18 \\
1 \\
- \\
-\end{array}$ & $\begin{array}{c}+0.172 \\
0.061\end{array}$ \\
\hline LOI & $\begin{array}{c}n \\
\text { Nall } \\
F_{I S} \\
P\end{array}$ & $\begin{array}{c}31 \\
5 \\
-0.038 \\
<10^{-4}\end{array}$ & $\begin{array}{c}32 \\
3 \\
-0.656 \\
<\mathbf{1 0}^{-4}\end{array}$ & $\begin{array}{r}26 \\
6 \\
+0.372 \\
0.003\end{array}$ & $\begin{array}{c}33 \\
2 \\
-0.174 \\
0.645\end{array}$ & $\begin{array}{r}34 \\
2 \\
-0.261 \\
0.214\end{array}$ & $\begin{array}{c}-0.149 \\
<10^{-4}\end{array}$ \\
\hline THU & $\begin{array}{c}n \\
\text { Nall } \\
F_{I S} \\
P\end{array}$ & $\begin{array}{c}17 \\
2 \\
-0.032 \\
1.00\end{array}$ & $\begin{array}{c}18 \\
3 \\
+0.243 \\
0.068\end{array}$ & $\begin{array}{c}12 \\
6 \\
+0.544 \\
0.008\end{array}$ & $\begin{array}{c}5 \\
1 \\
- \\
-\end{array}$ & $\begin{array}{r}20 \\
2 \\
+0.745 \\
0.003\end{array}$ & $\begin{array}{r}+0.441 \\
<10^{-3}\end{array}$ \\
\hline All & $\begin{array}{c}F_{I S} \\
P\end{array}$ & $\begin{array}{r}-0.187 \\
0.971\end{array}$ & $\begin{array}{r}-0.145 \\
<10^{-4}\end{array}$ & $\begin{array}{r}+0.324 \\
<10^{-4}\end{array}$ & $\begin{array}{r}+0.208 \\
<10^{-3}\end{array}$ & $\begin{array}{r}+0.060 \\
0.002\end{array}$ & \\
\hline $\begin{array}{l}\text { 3rd Coll } \\
\text { PHU }\end{array}$ & $\begin{array}{l}\text { on) } \\
n \\
\text { Nall } \\
F_{I S} \\
P\end{array}$ & $\begin{array}{c}12 \\
2 \\
-0.222 \\
1.00\end{array}$ & $\begin{array}{c}12 \\
3 \\
-0.304 \\
0.742\end{array}$ & $\begin{array}{c}12 \\
7 \\
+0.018 \\
0.341\end{array}$ & $\begin{array}{c}12 \\
3 \\
+0.656 \\
0.043\end{array}$ & $\begin{array}{r}12 \\
1 \\
- \\
-\end{array}$ & $\begin{array}{c}+0.403 \\
0.341\end{array}$ \\
\hline NHA & $\begin{array}{c}n \\
\text { Nall } \\
F_{I S} \\
P\end{array}$ & $\begin{array}{c}23 \\
3 \\
-0.226 \\
0.630\end{array}$ & $\begin{array}{c}23 \\
2 \\
-0.257 \\
0.538\end{array}$ & $\begin{array}{c}23 \\
5 \\
+0.508 \\
<\mathbf{1 0}^{-4}\end{array}$ & $\begin{array}{c}24 \\
2 \\
-0.278 \\
0.289\end{array}$ & $\begin{array}{r}24 \\
1 \\
- \\
-\end{array}$ & $\begin{array}{c}+0.048 \\
<10^{-4}\end{array}$ \\
\hline NBE & $\begin{array}{c}n \\
\text { Nall } \\
F_{I S} \\
P\end{array}$ & $\begin{array}{c}24 \\
3 \\
-0.214 \\
0.631\end{array}$ & $\begin{array}{c}24 \\
2 \\
-0.211 \\
0.551\end{array}$ & $\begin{array}{c}24 \\
7 \\
+0.164 \\
0.245\end{array}$ & $\begin{array}{c}24 \\
2 \\
-0.040 \\
1.00\end{array}$ & $\begin{array}{c}24 \\
2 \\
-0.070 \\
1.00\end{array}$ & $\begin{array}{c}-0.022 \\
0.896\end{array}$ \\
\hline BIN & $\begin{array}{c}n \\
\text { Nall } \\
F_{I S} \\
P\end{array}$ & $\begin{array}{c}18 \\
2 \\
-0.030 \\
1.00\end{array}$ & $\begin{array}{c}19 \\
5 \\
+0.047 \\
0.009\end{array}$ & $\begin{array}{c}30 \\
8 \\
+0.259 \\
\mathbf{0 . 0 0 1}\end{array}$ & $\begin{array}{c}24 \\
2 \\
+0.711 \\
0.004\end{array}$ & $\begin{array}{c}22 \\
2 \\
-0.077 \\
1.00\end{array}$ & $\begin{array}{r}+0.244 \\
<10^{-3}\end{array}$ \\
\hline $\mathrm{BCH}$ & $\begin{array}{c}n \\
\text { Nall } \\
F_{I S} \\
P \\
\text { Null }\end{array}$ & $\begin{array}{c}22 \\
3 \\
-0.140 \\
1.00 \\
0\end{array}$ & $\begin{array}{c}23 \\
3 \\
-0.182 \\
0.004 \\
0.583\end{array}$ & $\begin{array}{c}23 \\
6 \\
+0.307 \\
0.183 \\
0.340\end{array}$ & $\begin{array}{c}23 \\
2 \\
-0.100 \\
1.00 \\
0.0003\end{array}$ & $\begin{array}{c}23 \\
1 \\
- \\
- \\
-\end{array}$ & $\begin{array}{c}+0.055 \\
0.068\end{array}$ \\
\hline LOI & $\begin{array}{c}n \\
\text { Nall } \\
F_{I S} \\
P\end{array}$ & $\begin{array}{c}20 \\
2 \\
- \\
-\end{array}$ & $\begin{array}{c}22 \\
3 \\
-0.000 \\
1.00\end{array}$ & $\begin{array}{c}21 \\
6 \\
+0.187 \\
0.165\end{array}$ & $\begin{array}{c}10 \\
2 \\
-0.125 \\
1.00\end{array}$ & $\begin{array}{r}23 \\
1 \\
- \\
-\end{array}$ & $\begin{array}{c}+0.093 \\
0.730\end{array}$ \\
\hline THU & $\begin{array}{c}n \\
\text { Nall } \\
F_{I S} \\
P\end{array}$ & $\begin{array}{c}24 \\
2 \\
+0.840 \\
<\mathbf{1 0}^{-4}\end{array}$ & $\begin{array}{c}17 \\
3 \\
-0.354 \\
0.309\end{array}$ & $\begin{array}{c}13 \\
5 \\
+0.469 \\
0.033\end{array}$ & $\begin{array}{c}12 \\
3 \\
+0.651 \\
0.044\end{array}$ & $\begin{array}{c}17 \\
2 \\
-0.067 \\
1.00\end{array}$ & $\begin{array}{r}+0.403 \\
<10^{-3}\end{array}$ \\
\hline All & $\begin{array}{c}F_{I S} \\
P\end{array}$ & $\begin{array}{c}+0.120 \\
0.027\end{array}$ & $\begin{array}{c}-0.168 \\
0.025\end{array}$ & $\begin{array}{r}+0.285 \\
<10^{-4}\end{array}$ & $\begin{array}{c}+0.175 \\
0.027\end{array}$ & $\begin{array}{c}-0.071 \\
1.00\end{array}$ & \\
\hline
\end{tabular}

$n=$ sample size; Nall = number of alleles per locus; $F_{I S}=$ the inbreeding coefficient, measures the reduction of heterozygosity of a subpopulation due to non-random mating; $P$ = probability for rejecting Hardy-Weinberg equilibrium using Fisher's exact test; Probabilities significant after correction using Bonferroni's method are in bold. 
Table 5 Aedes aegypti differentiation according to season, as shown by isoenzyme and microsatellite polymorphism analysis

\begin{tabular}{|c|c|c|c|c|}
\hline \multirow[t]{2}{*}{ Collection } & \multicolumn{3}{|c|}{ Isoenzymes $F_{S T}(P)$} & \multirow{2}{*}{$\begin{array}{c}\text { Microsatellites } F_{S T}(P) \\
\text { All }^{c}\end{array}$} \\
\hline & All & Rainy season ${ }^{a}$ & Dry season ${ }^{b}$ & \\
\hline All populations & $\begin{array}{c}0.049 \\
\left(<10^{-6}\right)\end{array}$ & $\begin{array}{l}0.016 \\
\left(<10^{-6}\right)\end{array}$ & $\begin{array}{c}0.081 \\
\left(<10^{-6}\right)\end{array}$ & $\begin{array}{c}0.040 \\
\left(<10^{-6}\right)\end{array}$ \\
\hline 1. PHU & $\begin{array}{c}0.089 \\
\left(<10^{-6}\right)\end{array}$ & $\begin{array}{c}0.017 \\
\left(<10^{-4}\right)\end{array}$ & $\begin{array}{c}0.239 \\
\left(<10^{-6}\right)\end{array}$ & $\begin{array}{c}0.122 \\
(0.001)\end{array}$ \\
\hline 2. NHA & $\begin{array}{c}0.018 \\
\left(<10^{-6}\right)\end{array}$ & $\begin{array}{c}0.025 \\
\left(<10^{-4}\right)\end{array}$ & $\begin{array}{c}0.012 \\
(0.005)\end{array}$ & $\begin{array}{c}0.117 \\
\left(<10^{-6}\right)\end{array}$ \\
\hline 3. NBE & $\begin{array}{l}0.058 \\
\left(<10^{-6}\right)\end{array}$ & $\begin{array}{c}0.019 \\
\left(<10^{-6}\right)\end{array}$ & $\begin{array}{c}0.118 \\
\left(<10^{-6}\right)\end{array}$ & $\begin{array}{l}0.102 \\
\left(<10^{-6}\right)\end{array}$ \\
\hline 4. BIN & $\begin{array}{c}0.044 \\
\left(<10^{-6}\right)\end{array}$ & $\begin{array}{c}0.029 \\
\left(<10^{-6}\right)\end{array}$ & $\begin{array}{c}0.081 \\
\left(<10^{-6}\right)\end{array}$ & $\begin{array}{c}0.224 \\
\left(<10^{-6}\right)\end{array}$ \\
\hline 5. $\mathrm{BCH}$ & $\begin{array}{c}0.071 \\
\left(<10^{-6}\right)\end{array}$ & $\begin{array}{c}0.017 \\
(0.014)\end{array}$ & $\begin{array}{c}0.243 \\
\left(<10^{-6}\right)\end{array}$ & $\begin{array}{c}0.180 \\
\left(<10^{-6}\right)\end{array}$ \\
\hline 6. LOI & $\begin{array}{c}0.054 \\
\left(<10^{-6}\right)\end{array}$ & $\begin{array}{c}0.010 \\
(0.076)\end{array}$ & $\begin{array}{c}0.060 \\
\left(<10^{-3}\right)\end{array}$ & $\begin{array}{c}0.092 \\
\left(<10^{-6}\right)\end{array}$ \\
\hline 7. THU & $\begin{array}{c}0.043 \\
\left(<10^{-6}\right)\end{array}$ & $\begin{array}{c}0.010 \\
(0.033)\end{array}$ & $\begin{array}{c}0.065 \\
\left(<10^{-4}\right)\end{array}$ & $\begin{array}{c}0.138 \\
\left(<10^{-4}\right)\end{array}$ \\
\hline
\end{tabular}

${ }^{a}$ Collections 1, 2 and 5; ${ }^{\mathrm{b}}$ collections 3 and 4; ${ }^{\mathrm{c}}$ collections 1 and 3; $P$ = Probability of homogeneity (see text for more details).

often stored in jars, which function as permanent breeding sites throughout the year. Most of the dwellings in the city centre have running water, so deliberate attempts to store water are rare. Most of the larval habitats in the city centre are small containers discarded or dumped close to dwellings, and this creates a strong correlation between mosquito density and rainfall (Trpis, 1972). Once the dry season begins, the number of available temporary breeding sites decreases and the mosquito population crashes. Populations colonizing the small containers that predominate in the city centre decrease at the beginning of the dry season (at the time of the 3rd collection). However, in the suburbs, populations in small containers are drastically reduced, but those living in jars permanently filled with stored water only decrease at the end of the dry season. Populations in permanent water storage jars may display considerable gene flow, with genetic differentiation decreasing at the end of the dry season only if sufficient temporary breeding sites are available to facilitate dispersal.

Large decreases in the population during the dry season are certainly followed by recolonization in the following rainy season from permanent breeding sites such as water jars or from temporary breeding sites progressively filled by rain. Later in the rainy season (at the time of the 5 th collection), residual populations colonize all breeding sites and genetic differentiation becomes less significant. Colonizing groups in the city and suburbs seem to have a similar genetic constitution.

In one sample (NHA) from the Nha Be district, we found the opposite pattern of temporal variation. Nha Be is a rural area $10 \mathrm{~km}$ from the centre Ho Chi Minh City. This district is known to be infested with malaria. Inhabitants use permethrin-impregnated nets to protect themselves against anopheline mosquitoes. Huber et al (2000) found that the frequency of resistance to permethrin was higher in Aedes populations collected in Nha Be than in those from other districts. If genetic bottlenecks due to insecticide treatments reduce the genetic variability of populations, as observed by Lerdthusnee and Chareonviriyaphap (1999), this may account for the lack of differentiation in samples from the 3rd collection during the dry season. Selection by insecticides may reduce the genetic diversity of the population at loci conferring insecticide resistance and at other surrounding loci via the genetic hitchhiking effect (Yan et al, 1998). Individuals from neighbouring untreated populations with higher densities (more breeding sites) in areas of dense human populations (Paupy et al, 2000) may be responsible for recolonization. This would result in greater genetic exchange between populations and a decrease in the level of genetic differentiation, as observed in the Nha Be population. Moreover, this lower level of genetic differentiation is correlated with high and homogeneous infection rates. Two of the three heterozygote deficits at microsatellite loci observed in the 1st collection and one of the three observed in the 3rd collection concerned samples collected in Nha Be District. Insecticide treatment, killing entire populations, may decrease the time required to fix an allele within a population by increasing homozygosity (and decreasing heterozygosity) (K Huber, personal communication)

The numerous rare alleles observed at microsatellite loci correlated with a change in allelic composition between the two collections also underline the role of migration in determining the genetic structure. Until the mutation-drift equilibrium is restored, new mutations subject to selection remain detectable in populations as rare alleles (Schlötterer and Wiehe, 1999). Nevertheless, the effect of a given locus under selection on gene diversity, as estimated from microsatellite polymorphism, depends on the degree of linkage between the selected locus and the microsatellite (Schlötterer et al, 1997). However, this phenomenon cannot account for the large changes in allelic frequencies observed on the time scale studied here. The migration of individuals may play a 
key role in the change in allelic composition. According to all these data, the observed genetic variation in Ae. aegypti populations may result from alternation between extinction and recolonization processes, consistent with metapopulation functioning (Barton and Whitlock, 1997).

Studies on temporal variation in population differentiation may provide insights into population dynamics over and above that provided by geographic analyses (Tran Khanh Tien et al, 1999; K Huber, personal communication). Such studies provide an opportunity to validate results obtained in geographic surveys performed at a single time point and also provide information about the main forces responsible for genetic changes in the short term. The findings of this study have direct implications for the forecasting of dengue outbreaks and the implementation of control strategies. Genetic differentiation and differences in infection rates decreased during the rainy season, when mosquito population densities were at their highest level. This strongly facilitates the dissemination of dengue. If insecticide treatments are initiated at the end of the dry season, when Ae. aegypti populations are highly differentiated and have low densities, efforts should be concentrated on the source population (populations from permanent breeding sites such as water storage jars) and/or migrants likely to become established. A large proportion of the Ae. aegypti population of urban centres is present in the form of eggs at this time of the year. Therefore, efforts to reduce source populations should focus on the elimination of both breeding sites and residual eggs. The greater genetic exchange observed between populations during the rainy season makes it necessary to pay attention to the occurrence and spread of selected traits, such as insecticide resistance. The migration of dengue-infected people is likely to disseminate dengue viruses more quickly than the migration of infected Ae. aegypti mosquitoes. Finally, other factors related to viruses and human populations should be considered to increase the accuracy of prediction of the level of dengue transmission.

\section{Acknowledgments}

We would like to thank Laurence Mousson and Marie Vazeille for technical assistance, and Christophe Paupy for valuable comments. We would also like to thanks Prof Ha Ba Khiem, director of the Pasteur Institute in Ho Chi Minh City, for his support. We also thank Prof Jean-Luc Durosoir, Délégué Général au Réseau International des Instituts Pasteur et Instituts Associés, for financial support (Grant ACIP no. 41192).

\section{References}

Barton NH, Whitlock MC (1997). The evolution of metapopulation. In: Hanski IA, Gilpin ME (eds) Metapopulation Biology, Academic Press: New York. pp 183-210.

Bernard PN, Bauche J (1913). Conditions de la propagation de la filariose sous-cutanée du chien. Stegomyia fasciata hôte intermédiaire de Dirofilaria repens. Bull Soc Path Exot 6: 89-99.
Holm S (1979). A simple sequentially rejective multiple test procedure. Scand J Stat 6: 65-70.

Huber K, Luu Le Loan, Tran Huu Hoang, Tran Khan Tien, Rodhain, F, Failloux A-B (2000). Aedes (Stegomyia) aegypti (L., 1762) (Diptera: Culicidae), le principal vecteur des virus de la dengue au Vietnam: écologie, structure génétique, compétence vectorielle et résistance aux insecticides. Ann Soc Entomol Fr 36: 109-120.

Huber K, Mousson L, Rodhain F, Failloux A-B (2001). Isolation and variability of polymorphic microsatellite loci in Aedes aegypti, the vector of dengue viruses. Mol Ecol Notes 1: 219222.

Lerdthusnee K, Chareonviriyaphap T (1999). Comparison of isozyme patterns of Aedes aegypti populations collected from preand post-Bacillus thuringiensis israelensis treatment sites in Thailand. J Am Mosq Control Assoc 15: 48-52.

Mihov C, Chu Van Tuong, Hoang Phuc Tuong (1959). A propos d'une épidémie du type des fièvres hémorragiques à Hanoi. Folia Medica 1: 169-173.

Moore CG, Cline BL, Ruiz-Tiben E, Lee D, Romney-Joseph H, Rivera-Correa E (1978). Aedes aegypti in Puerto Rico: environmental determinants of larval abundance and relation to dengue virus transmission. Am J Trop Med Hyg 27: 1225-1231.

Ohta T (1982). Linkage disequilibrium due to random genetic drift in finite subdivided populations. Proc Natl Acad Sci USA 79: 1940-1944.

Pasteur N, Pasteur G, Bonhomme F, Catalan J, Britton-Davidian J (1988). Practical Isozyme Genetics, John Wiley and Sons/Ellis Horwood Ltd: Chichester, England.

Paupy C, Vazeille-Falcoz M, Mousson L, Rodhain F, Failloux AB (2000). Aedes aegypti in Tahiti and Moorea (French Polynesia): isoenzyme differentiation in the mosquito population according to human population density. Am J Trop Med Hyg 62: 217-224.

Raymond M, Rousset F (1995). GENEPOP (version 1.2): a population genetics software for exact tests and ecumenicism. $J$ Hered 86: 248-249.

Schlötterer C, Vogl C, Tautz D (1997). Polymorphism and locusspecific effects on polymorphism at microsatellite loci in natural Drosophila melanogaster populations. Genetics 146: 309-320.

Schlötterer C, Wiehe T (1999). Microsatellites, a neutral marker to infer selective sweeps. In Goldstein DB, Schlötterer C (eds) Microsatellites Evolution and Applications, Oxford University Press: Oxford, UK. pp 238-248.

Slatkin M (1985). Rare alleles as indicators of gene flow. Evolution, 39: 292-299.

Tran Khanh Tien, Vazeille-Falcoz M, Mousson L, Tran Huu Hoang, Rodhain F, Nguyen Thi Huong, Failloux A-B (1999). Aedes aegypti in Ho Chi Minh City (Viet Nam): susceptibility to dengue 2 virus and genetic differentiation. Trans Royal Soc Trop Med Hyg 93: 581-586.

Trpis M (1972). Seasonal changes in the larval populations of Aedes aegypti in two biotopes in Dar es Salaam, Tanzania. Bull WHO 47: 245-255.

Vazeille-Falcoz M, Mousson L, Rodhain F, Chungue E, Failloux A-B (1999). Variation in oral susceptibility to dengue type 2 virus of populations of Aedes aegypti from the islands of Tahiti and Moorea, French Polynesia. Am J Trop Med Hyg 60: 21-33.

Weir BS, Cockerham CC (1984). Estimating F-statistics for the analysis of population structure. Evolution 38: 1358-1370.

Yan G, Chadee DD, Severson DW (1998). Evidence for genetic hitchhiking effect associated with insecticide resistance in Aedes aegypti. Genetics 148: 793-800. 